This item was submitted to Loughborough's Research Repository by the author.

Items in Figshare are protected by copyright, with all rights reserved, unless otherwise indicated.

\title{
Investigation of zinc whisker growth from electrodeposits produced using an alkaline non-cyanide electroplating bath
}

PLEASE CITE THE PUBLISHED VERSION

\section{PUBLISHER STATEMENT}

This work is made available according to the conditions of the Creative Commons Attribution-NonCommercialNoDerivatives 4.0 International (CC BY-NC-ND 4.0) licence. Full details of this licence are available at: https://creativecommons.org/licenses/by-nc-nd/4.0/

\section{LICENCE}

CC BY-NC-ND 4.0

\section{REPOSITORY RECORD}

Wu, L., Mark A. Ashworth, and G.D. Wilcox. 2015. "Investigation of Zinc Whisker Growth from Electrodeposits Produced Using an Alkaline Non-cyanide Electroplating Bath”. figshare. https://hdl.handle.net/2134/19323. 


\title{
Investigation of Zinc Whisker Growth from Electrodeposits Produced Using an Alkaline Non-Cyanide Electroplating Bath
}

\author{
By Liang Wu \\ Co-authored by: \\ Dr Geoffrey D. Wilcox \\ Dr Mark A. Ashworth
}




\section{What is a Metallic Whisker?}

- Crystalline metallic crystals

- Spontaneously grow from metal surfaces (Sn, Zn, Cd)

- Reported average grow rate $\sim 250 \mu \mathrm{m}$ per year

- $1 \mu \mathrm{m}$ in diameter and a few millimetres in length

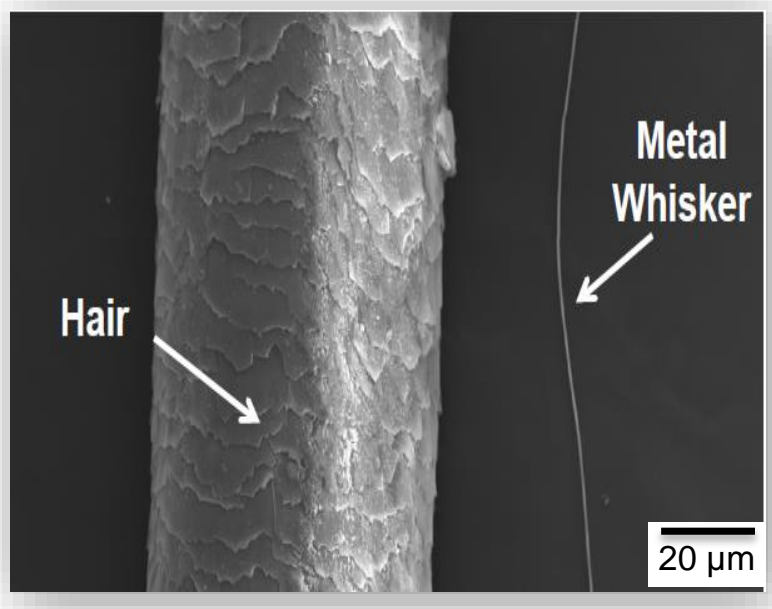

Able to form various shapes

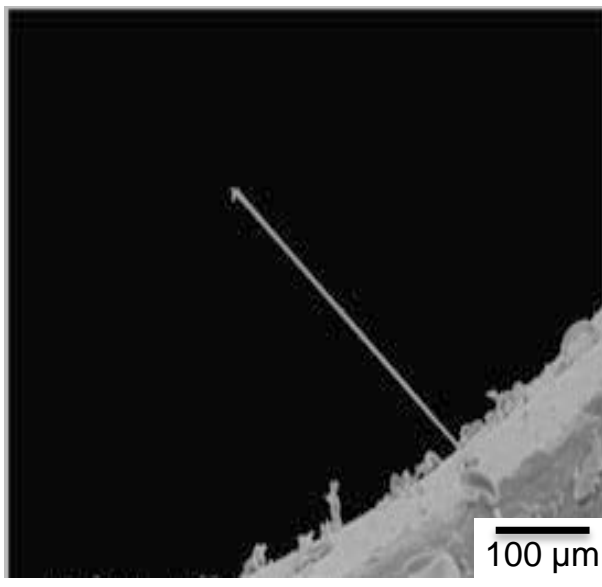

Straight

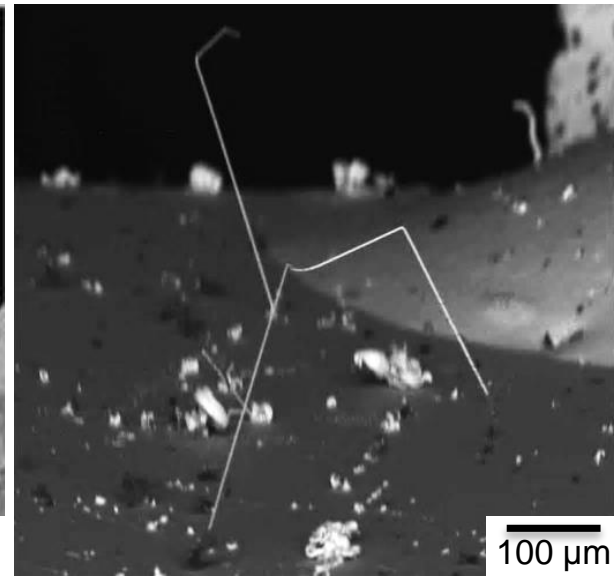

Kinked

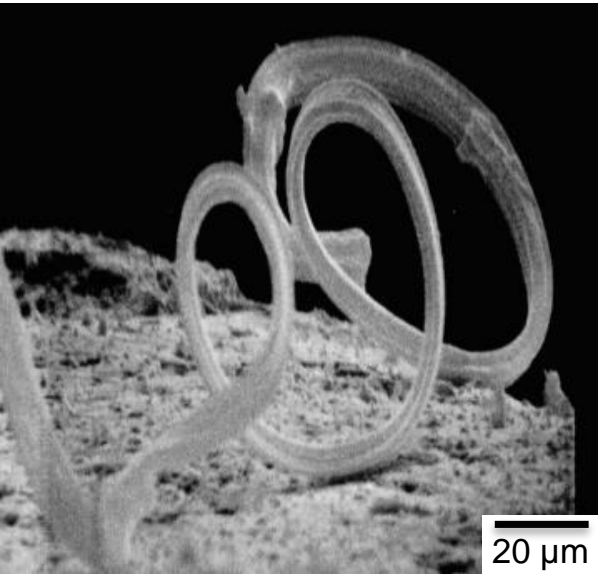

Spiral

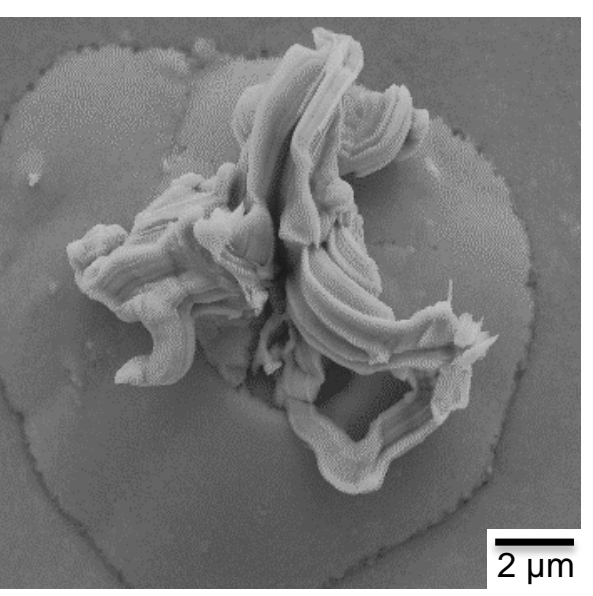

Curved eruption 


\section{Electronic Failures Caused by Whiskers}
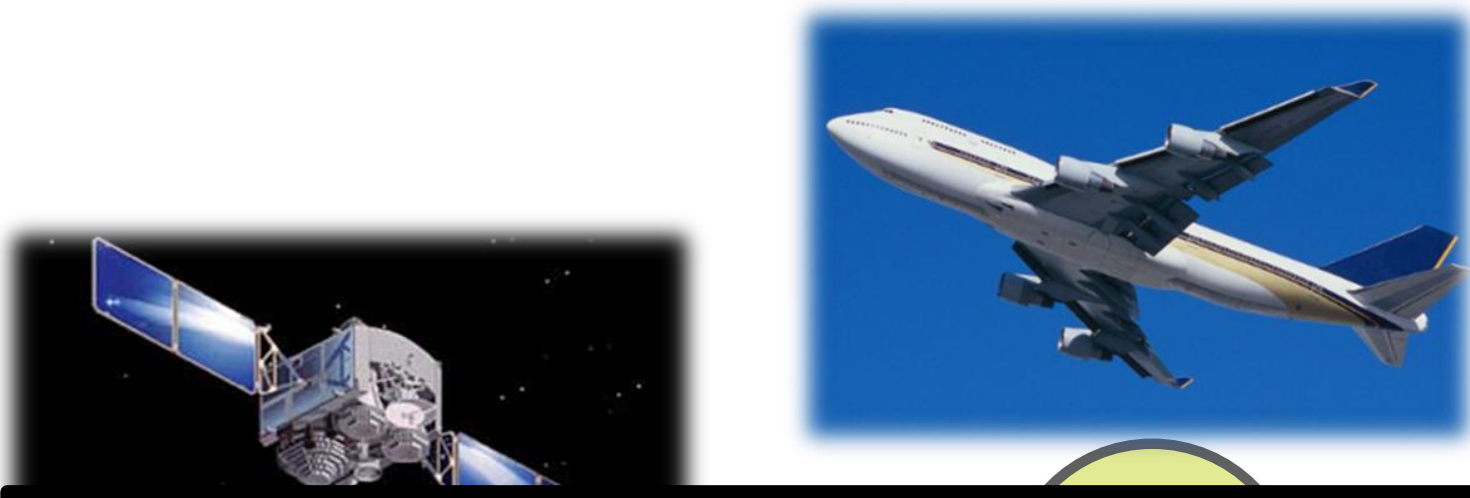

NASA: "50 Electronic Failures occurred due to Whisker Growth from 1986 - 2006; 10\% of the Problems We Know About!"
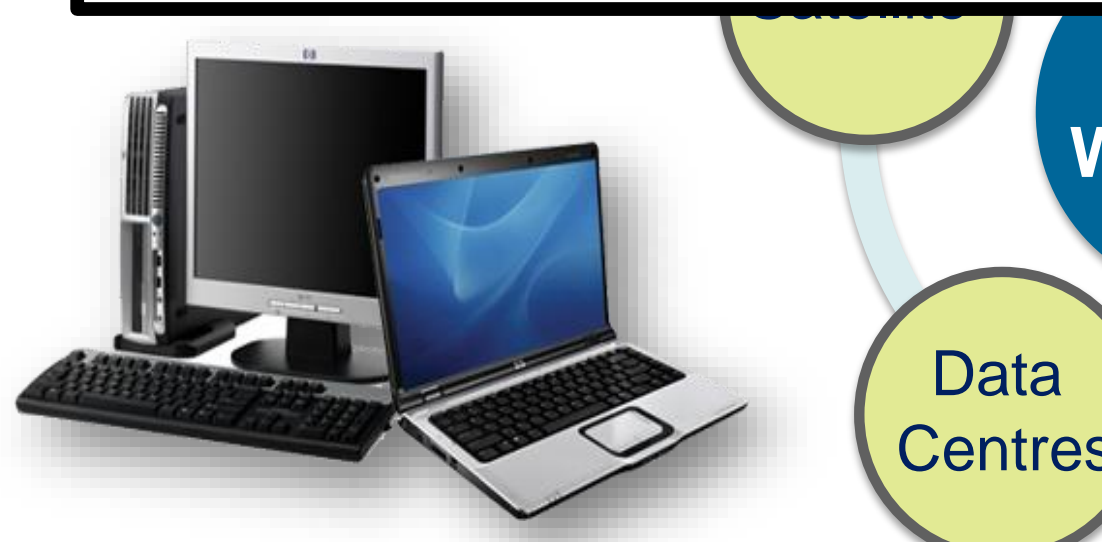

Metal Whiskers 


\section{Electronic Failures Caused by Zn Whiskers}

\begin{tabular}{|l|l|}
\hline Year & Whiskers on \\
\hline 1987 & Local Power Range Monitoring Detectors \\
\hline 1990 & Rotary Switch \\
\hline 1990 & Local Power Range Monitoring Detectors \\
\hline 1995 & Framework \\
\hline 1996 & Chassis \\
\hline 1998 & Chassis \\
\hline 1999 & Xsistor Package + Standoff \\
\hline 1999 & Chassis \\
\hline 2001 & Bus Rail \\
\hline 2003 & Floor Tiles \\
\hline 2004 & Floor Tiles \\
\hline 2004 & Floor Tiles \\
\hline 2012 & Floor Tiles \\
\hline
\end{tabular}

Applications

Dresden nuclear Power Station

Apnea Monitors

Duane Arnold Nuclear Power Station

Telecom Equipment

Computer Routers

Computer Hardware

Missiles

Computer Routers

Space Ground Test Equipment

Computer Data Centre in Canada

Computer Data Centre in USA

Computer Data Centre in Australia

Computer Data Centre in North East England

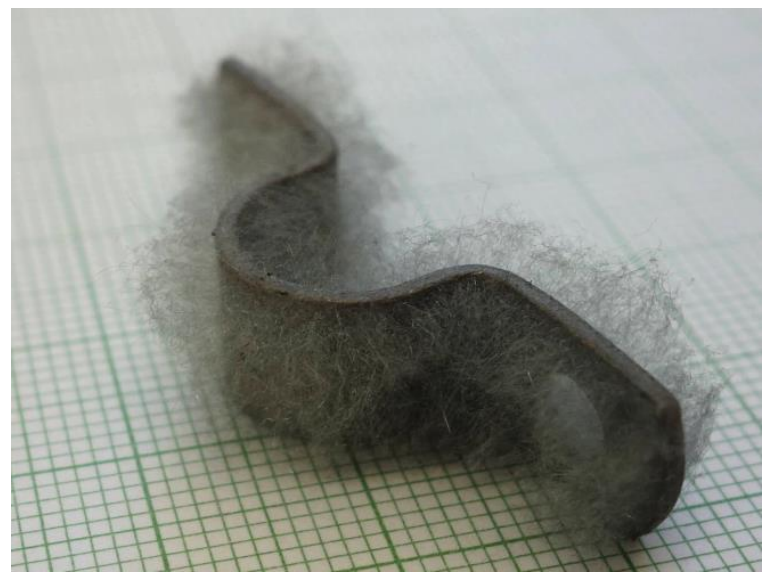

Many long zinc whiskers on zinc coated steel [1]

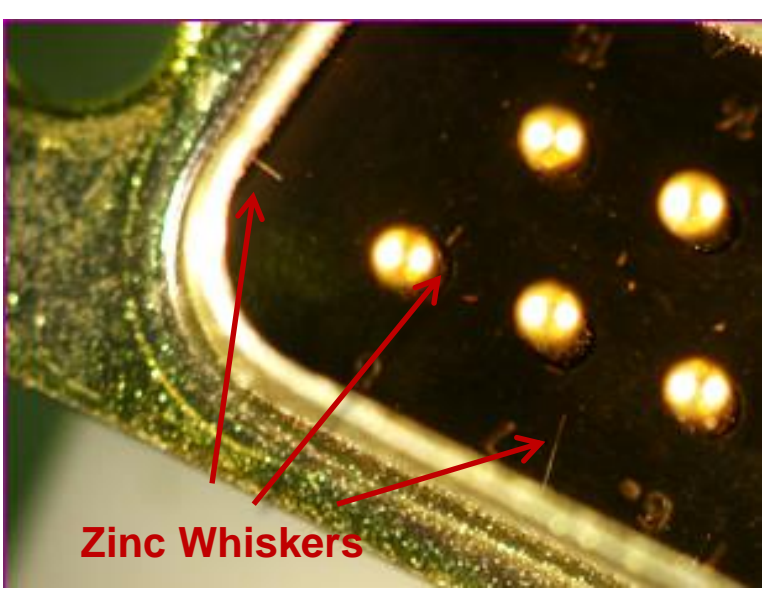

Zinc-electroplated connector shell [2] 


\section{Electronic Failure Mechanisms}

Type 1: Grown whiskers to bridge components

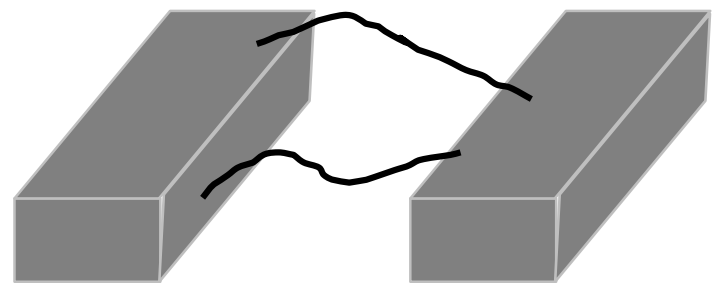

Type 2: Airborne whiskers settle on components
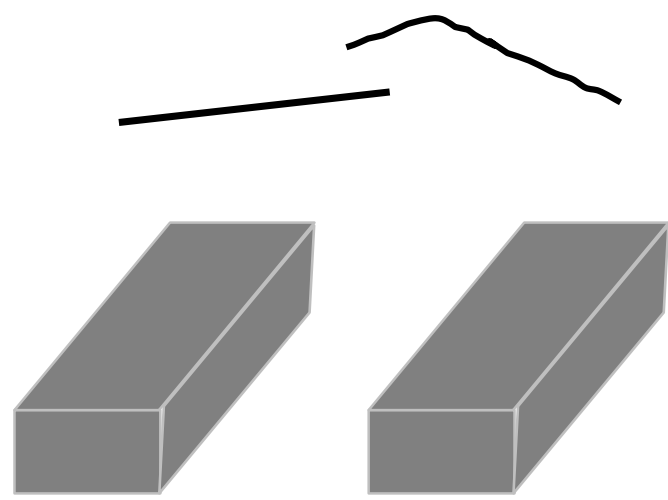

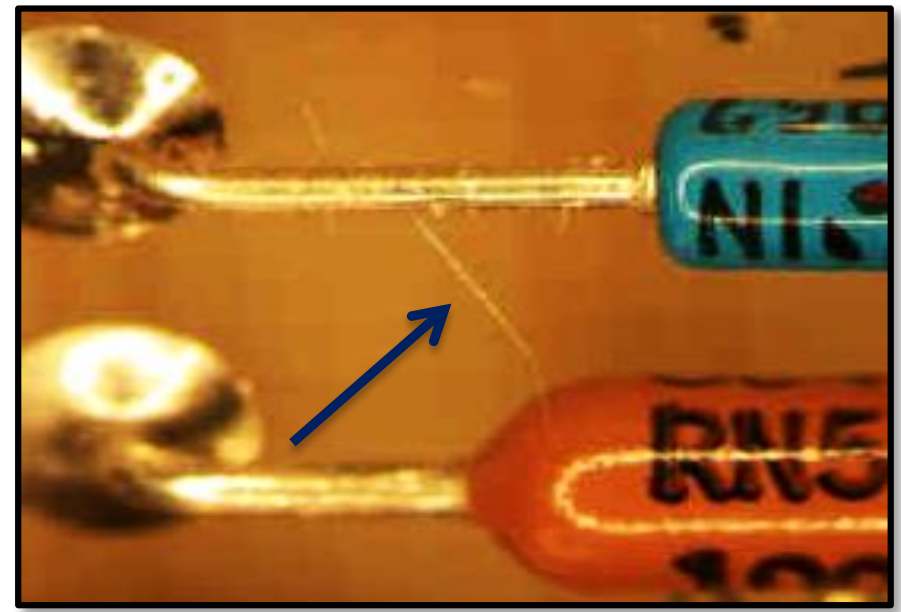

Type 1: A whisker grew and connected two diodes used in a nuclear power plant

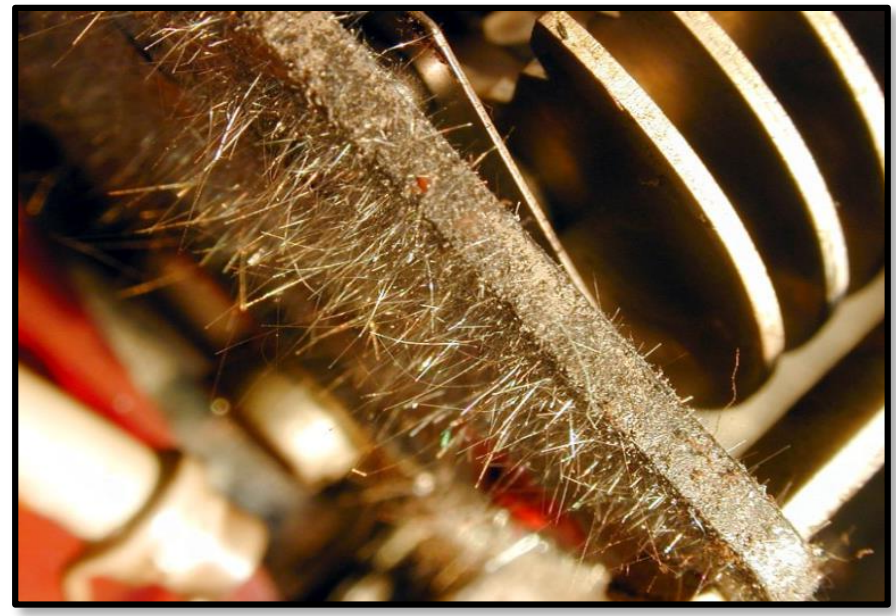

Type 2: Whiskers formed inside an air-spaced capacitor and became airborne whiskers
Produce a bridge between components

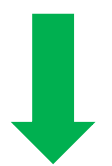

Short circuiting, voltage variance and other signal disturbance

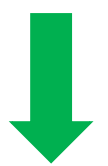

Electrical equipment failure 


\section{Objectives}

- Observe Zn whisker growth

- Growth rate and morphology

- Growth mechanisms

- Characterise the $\mathrm{Zn}$ electrodeposits

- Surface morphology

- Grain size and structure

In relation to whisker growth

- Investigate the influence of some key parameters on whisker growth

- Deposition current density

- Deposit thickness

- Post-electroplating thermal treatment 


\section{Experimental Approaches}

- Electroplating bath

Alkaline cyanide-free zinc plating solution

$$
\mathrm{pH} \sim 10
$$

\section{Chemicals}

\section{Zinc}

Sodium hydroxide

Conditioner

Brightener

\section{Purifier}

Initial additive

\section{Amount}

$11 \mathrm{~g} / \mathrm{l}$

$130 \mathrm{~g} / \mathrm{l}$

$30 \mathrm{ml} / \mathrm{l}$

$1.5 \mathrm{ml} / \mathrm{l}$

$1 \mathrm{ml} / \mathrm{l}$

$7 \mathrm{ml} / \mathrm{l}$

- Sample geometry

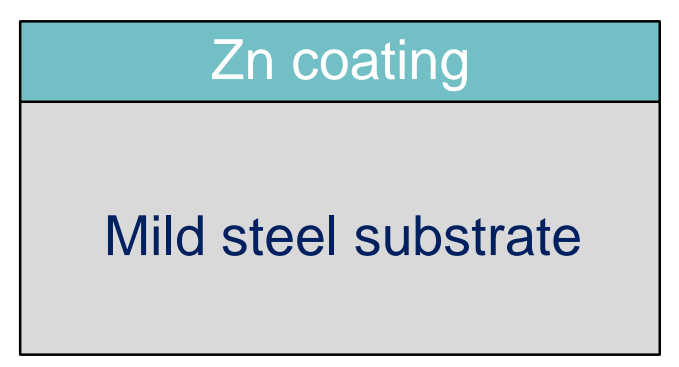

$\longleftarrow \sim 5 \mu \mathrm{m}$ thick (by electroplating)

- Sample storage

Room temperature $\left(\sim 20^{\circ} \mathrm{C}\right)$ 


\section{Effect of Deposition Current Density on Whisker Growth}

- SEM analysis 16 months after deposition

Number of whiskers $/ \mathrm{cm}^{2}$

$\left.\begin{array}{c}20000 \\ 5000 \\ 16000\end{array}\right] \quad$ Eilament-type whiskers

4000

12000

3000

800

2000

400 1000
- $5 \mu \mathrm{m}$ thick coating deposited at different current densities
Recommended current density range .
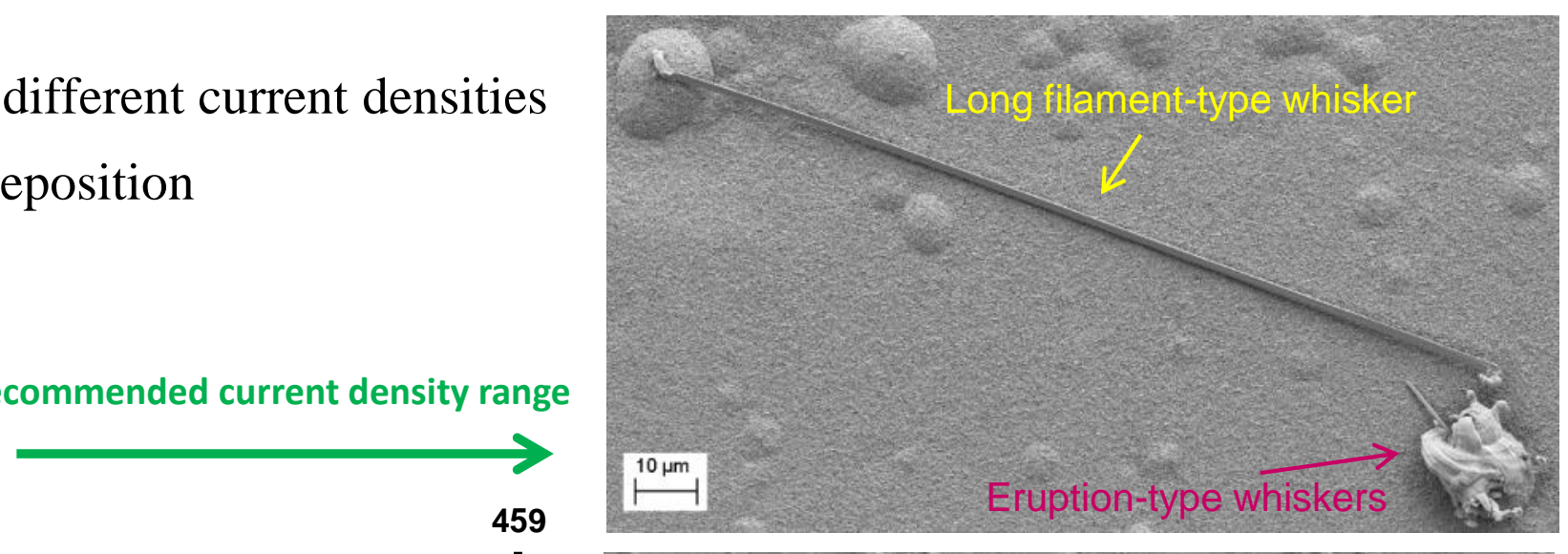

459

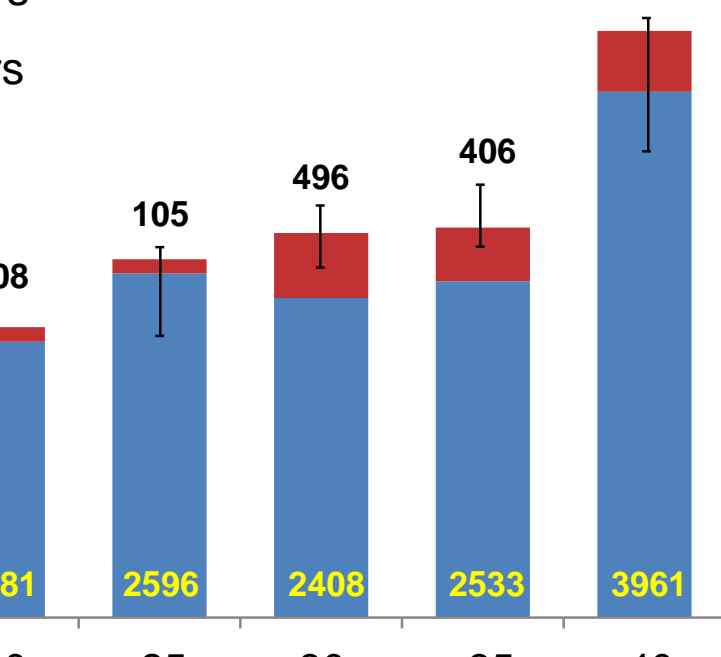

$\begin{array}{lll}20 & 25 \quad 30\end{array}$

35

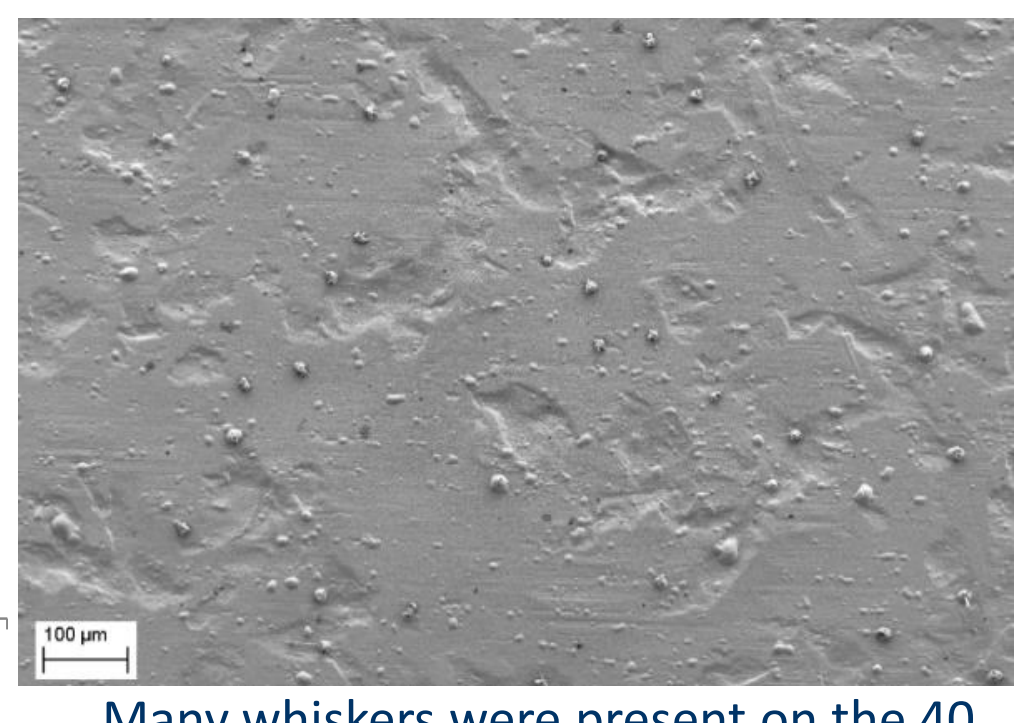

Deposition current density/mA.cm-2

Many whiskers were present on the 40 $\mathrm{mA} / \mathrm{cm}^{2}$ samples! 

University

\section{Effect of Deposition Current Density on Deposit Microstructure}

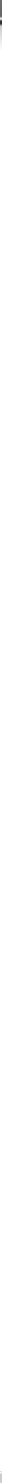



University

\section{Effect of Deposition Current Density on Deposit Microstructure}

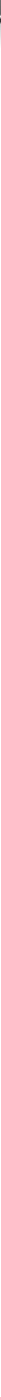

As current density increases: grain diameter decreases and more columnar structure 


\section{Effect of Deposit Thickness on Whisker Growth}

- Deposited at $25 \mathrm{~mA} / \mathrm{cm}^{2}$ with different thicknesses

- SEM analysis 13 months after deposition

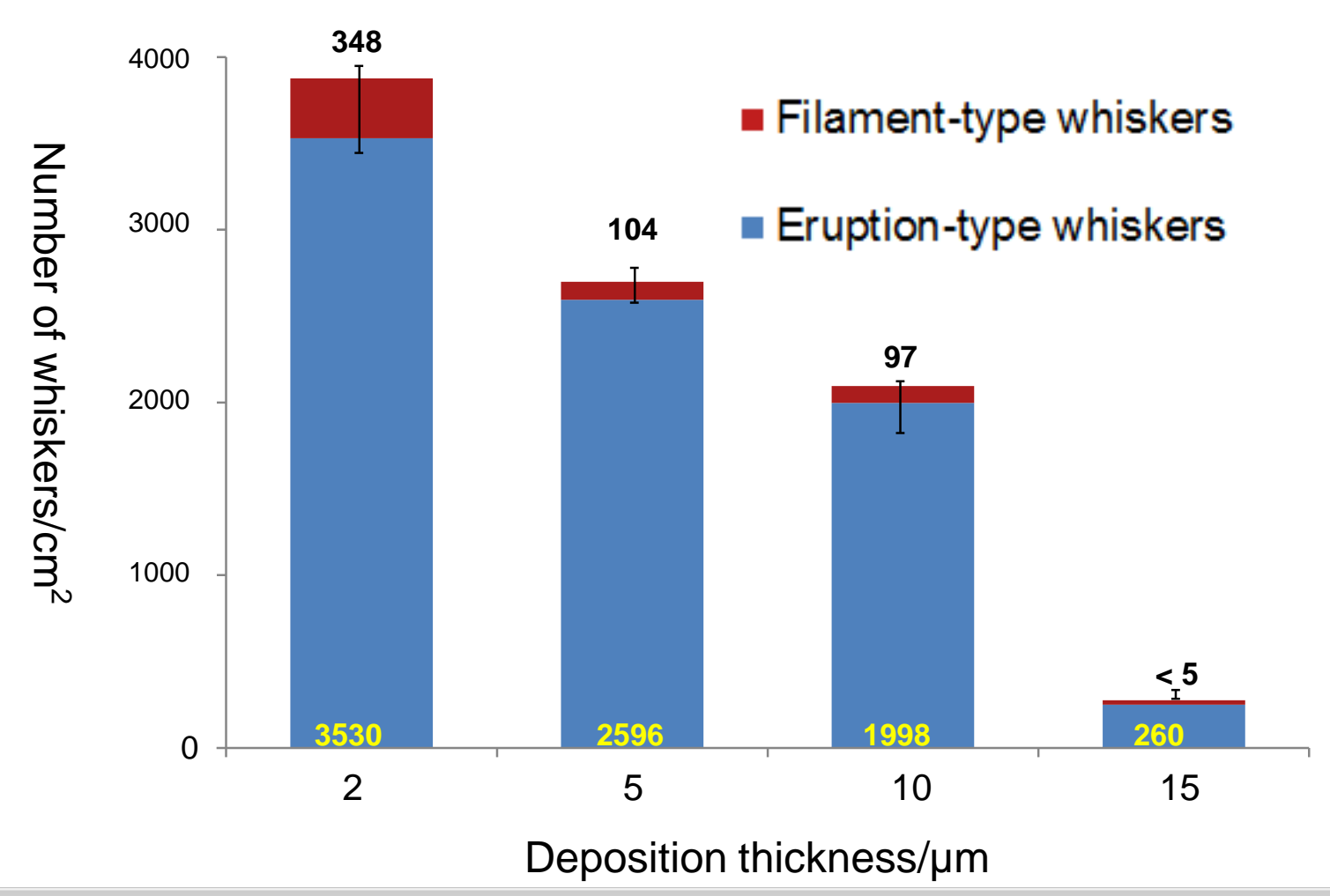

As deposit thickness increases

- Fewer filament-type whiskers

- Fewer eruption-type whiskers
Lower deposition current density \& thicker deposit result in fewer whiskers!



University

\section{Effect of Post-Electroplating Heat Treatment on Whisker Growth}

- Deposited at $25 \mathrm{~mA} / \mathrm{cm}^{2}$

- Thermal treated at different temps for $0.5 \mathrm{~h}$ and then storage at room temperature

- SEM analysis after 14 months

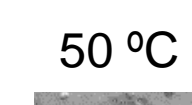

.

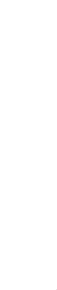



University

\section{Effect of Post-Electroplating Heat Treatment on Whisker Growth}

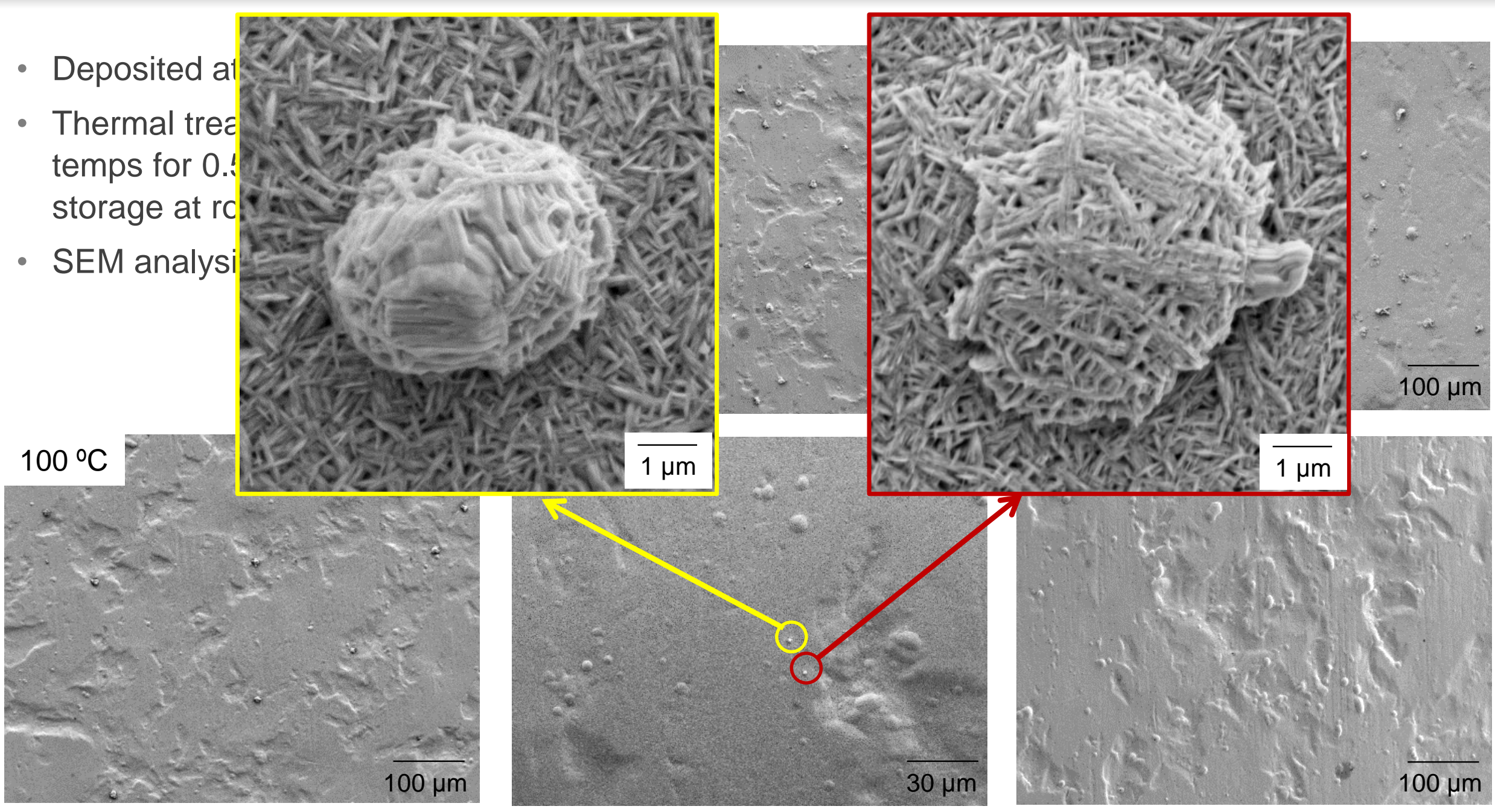



University

\section{Effect of Post-Electroplating Heat Treatment on Whisker Growth}

- Deposited at $25 \mathrm{~mA} / \mathrm{cm}^{2}$

- Thermal treated at different temps for $0.5 \mathrm{~h}$ and then storage at room temperature

- SEM analysis after 14 months Short period of heat treatment at high temp. markedly reduces whisker growth!

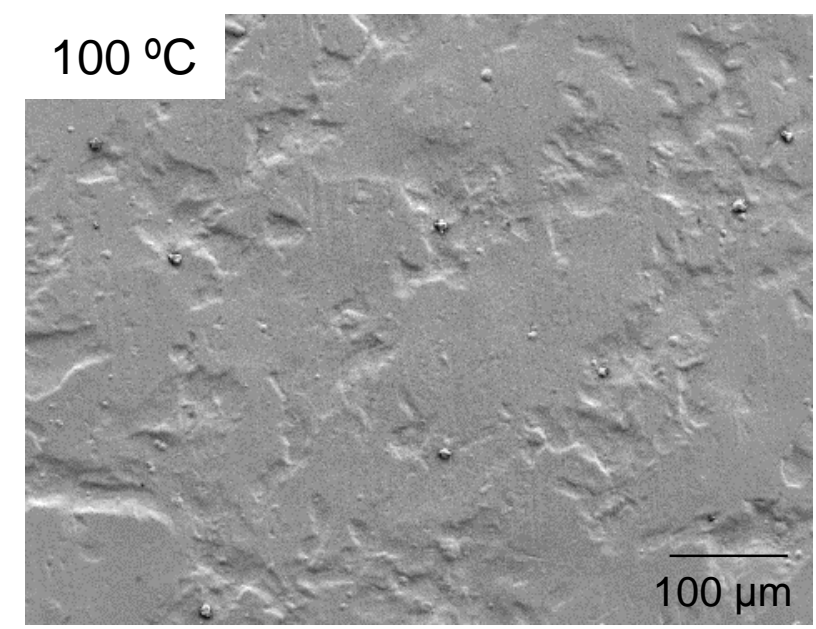

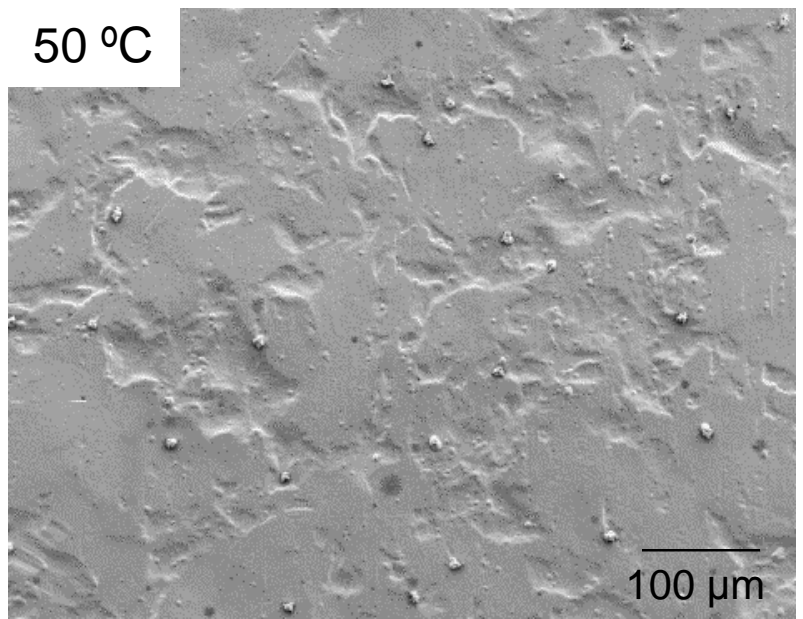
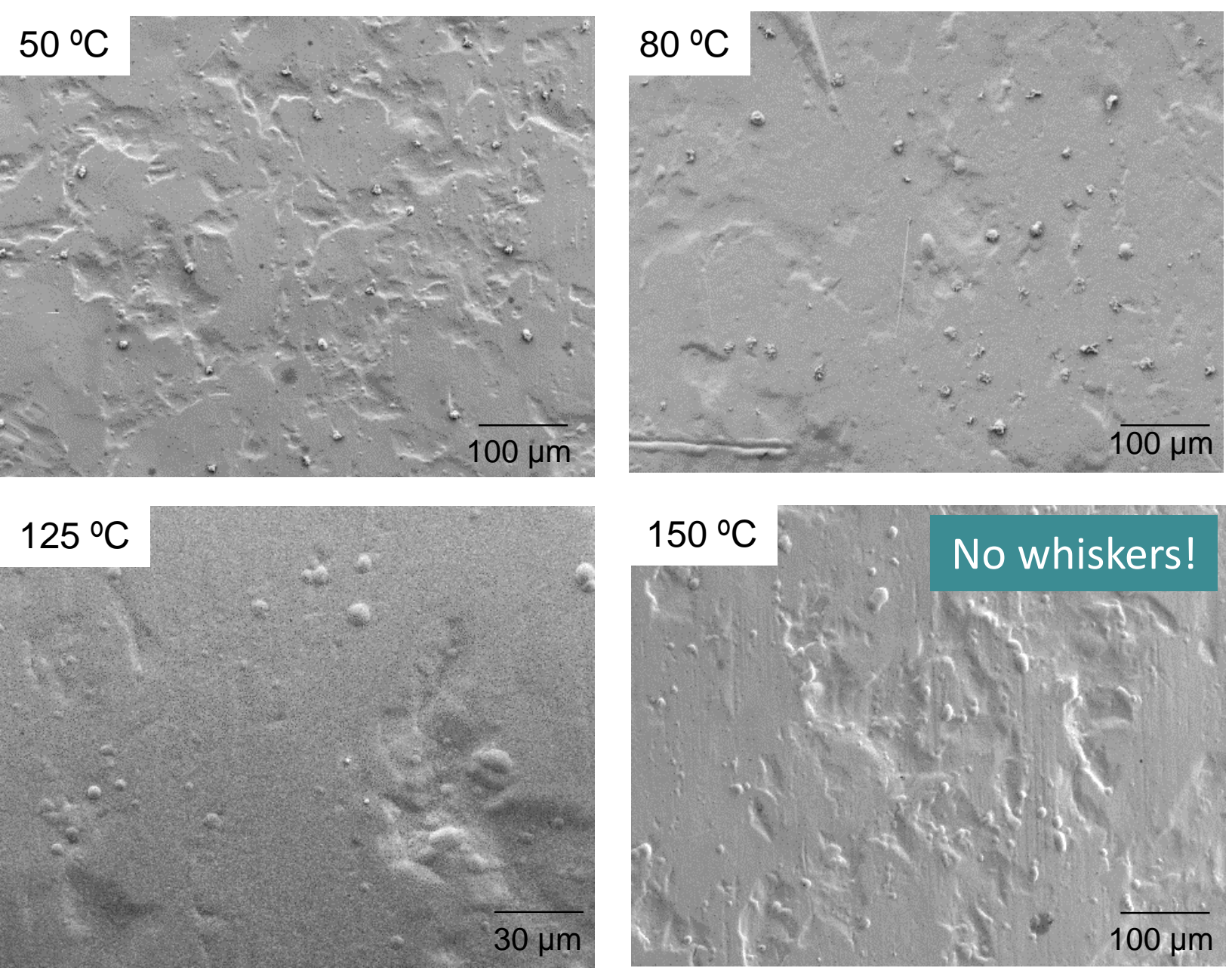


\section{Evolution of Whisker Growth at Room Temperature}

\section{$5 \mu \mathrm{m}$ alkaline zinc on mild steel electrodeposited at $25 \mathrm{~mA} / \mathrm{cm}^{2}$}

4 weeks after deposition

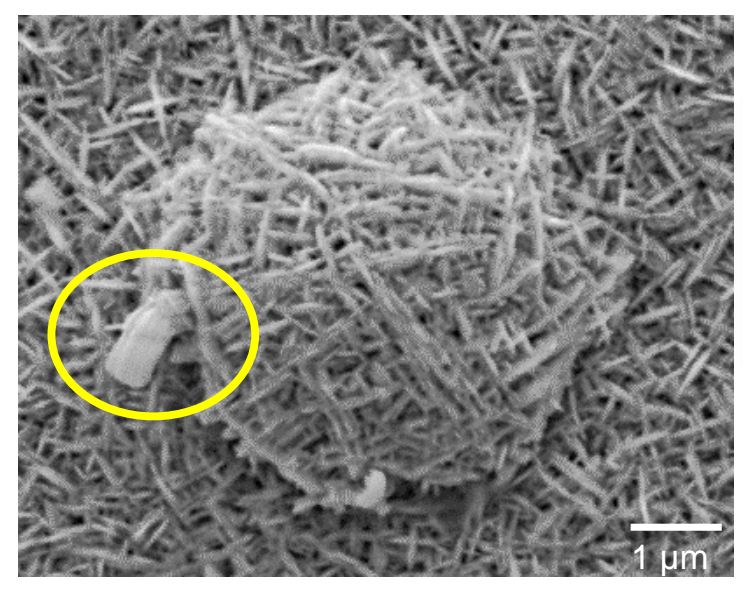

- Whiskers were present 4 weeks after deposition;

- 4 months after deposition, all the whiskers were growing associated with "nodules".
Many larger eruptions and longer whisker filaments present!
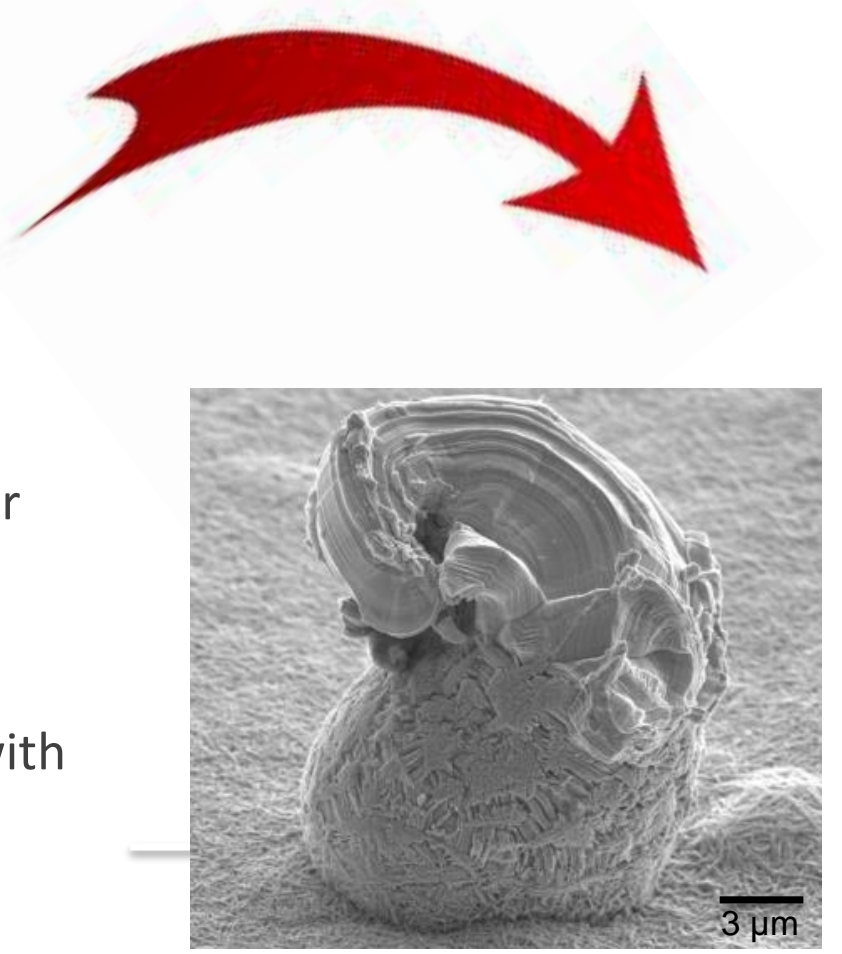

4 months after deposition
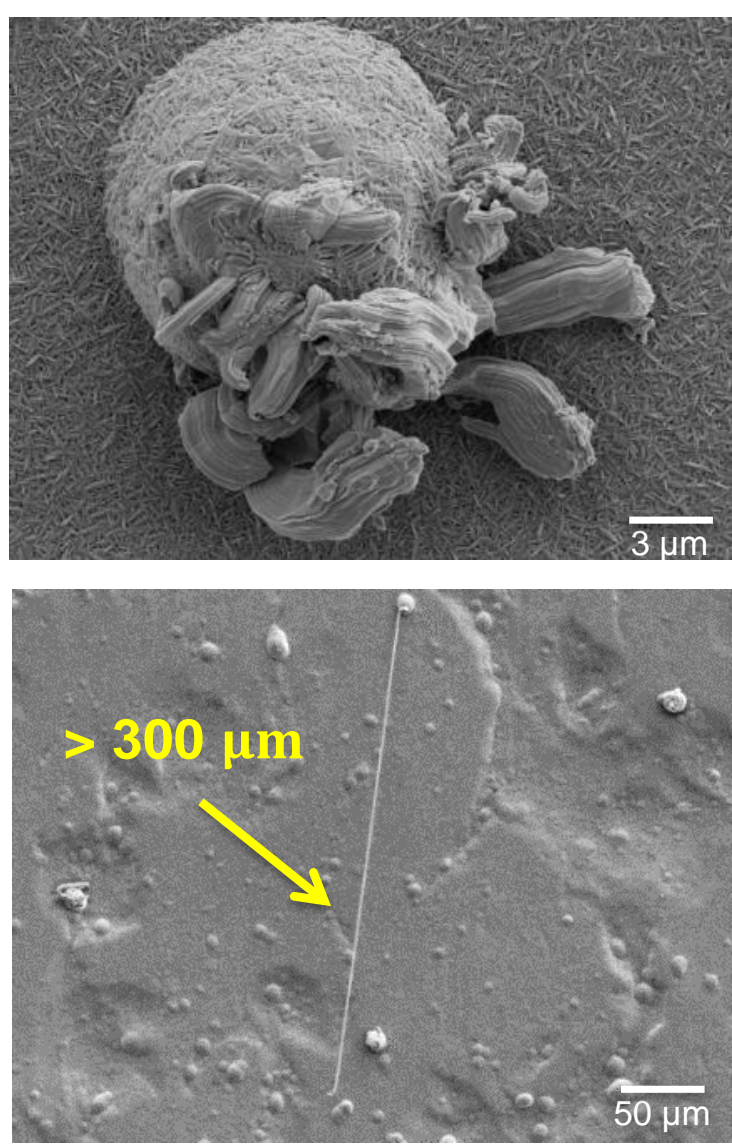

University

\section{Evolution of Whisker Growth at Room Temperature}

\section{$5 \mu \mathrm{m}$ alkaline zinc on mild steel electrodeposited at $25 \mathrm{~mA} / \mathrm{cm}^{2}$}

5 months after deposition

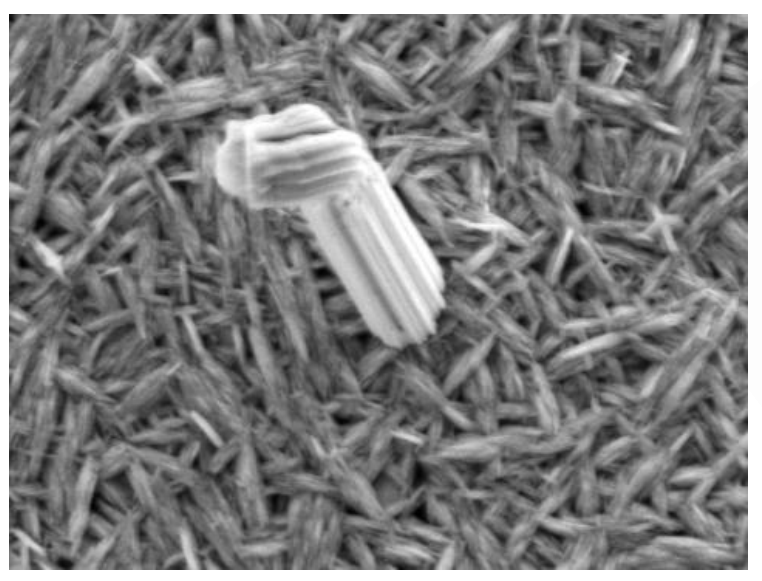

- Whiskers growing from the flat deposit surface were present 5 months after deposition;

- The presence of nodules markedly shortens the incubation time.
Many larger eruptions and longer whisker filaments present!
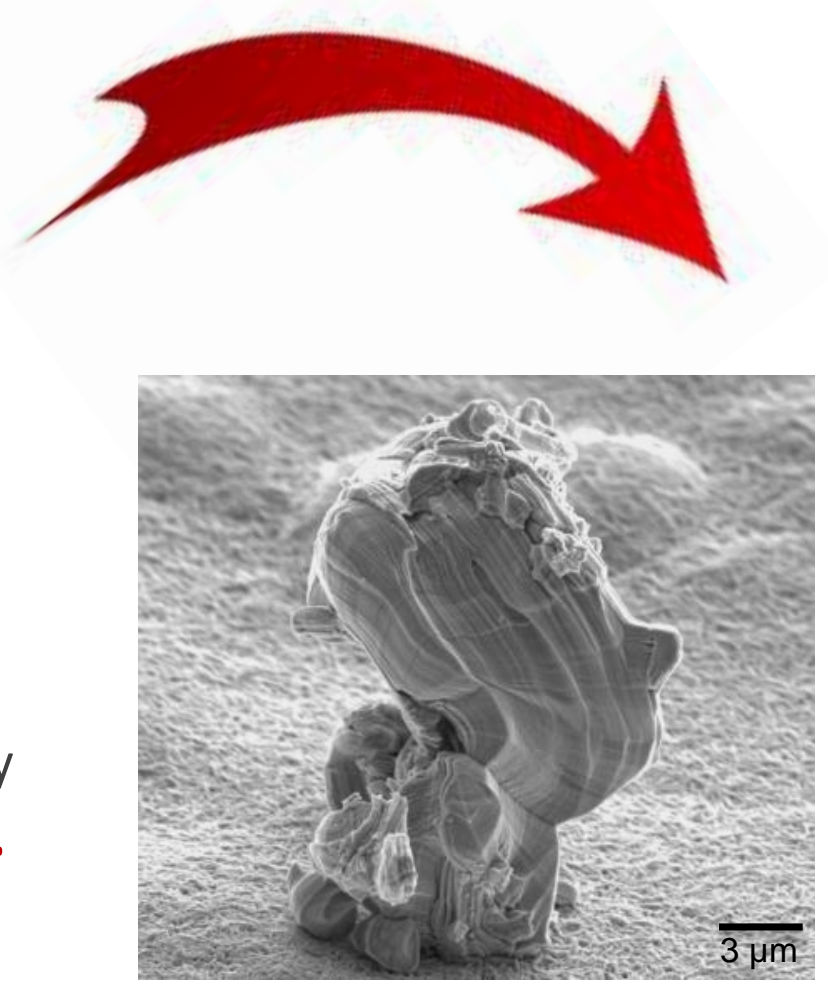

8 months after deposition
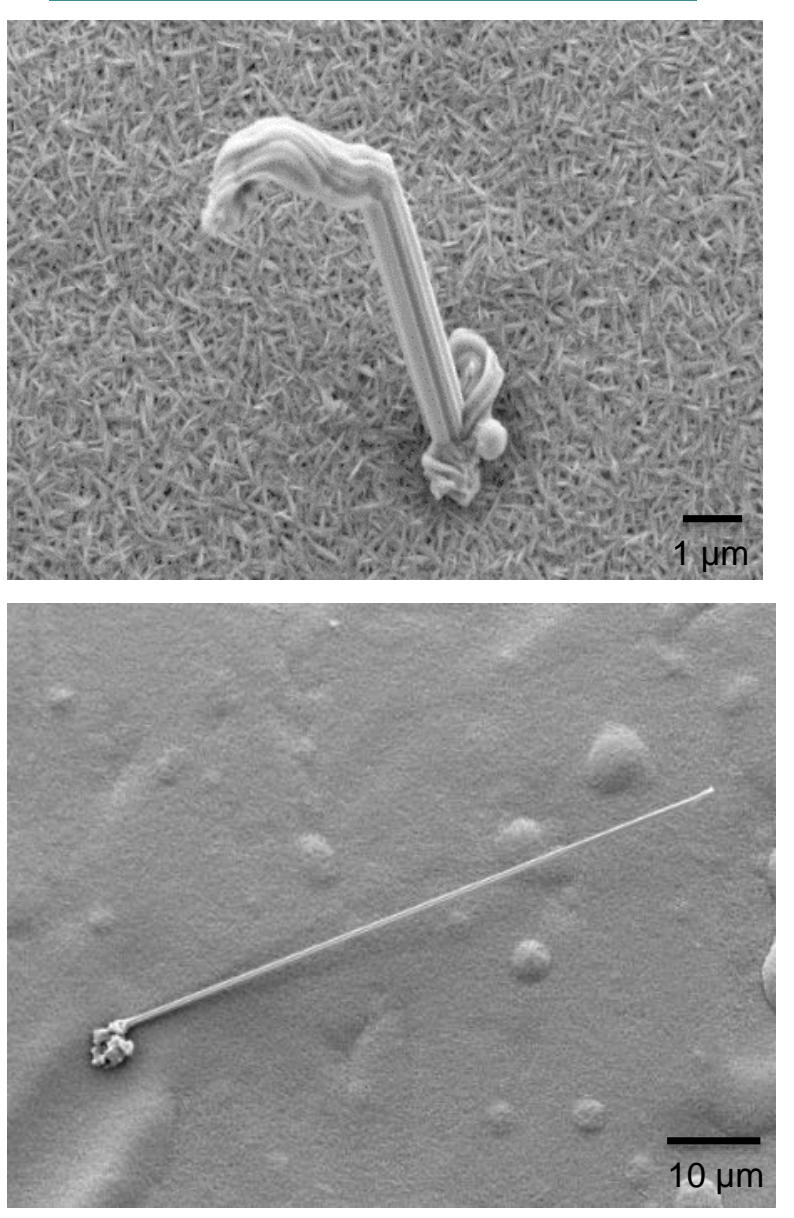


\section{Periodic Analysis of Whisker Growth Associated with Nodules}

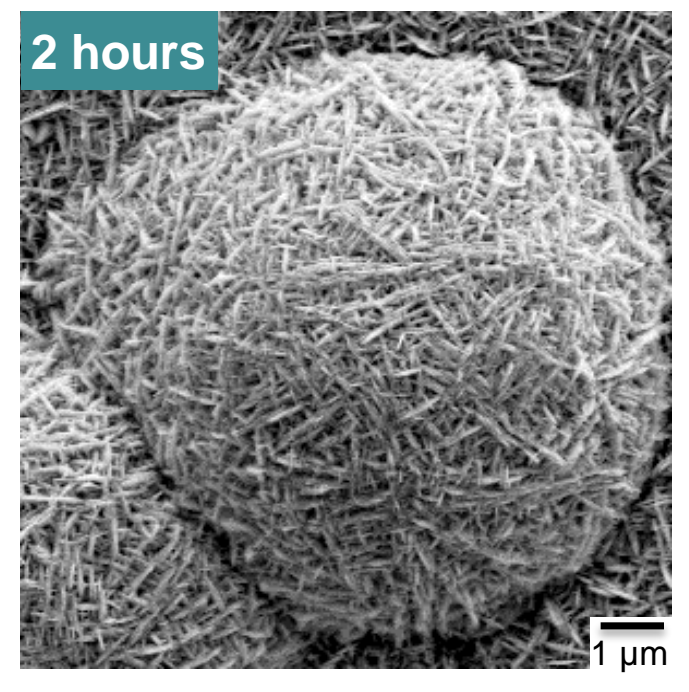

Several specific nodules were monitored periodically
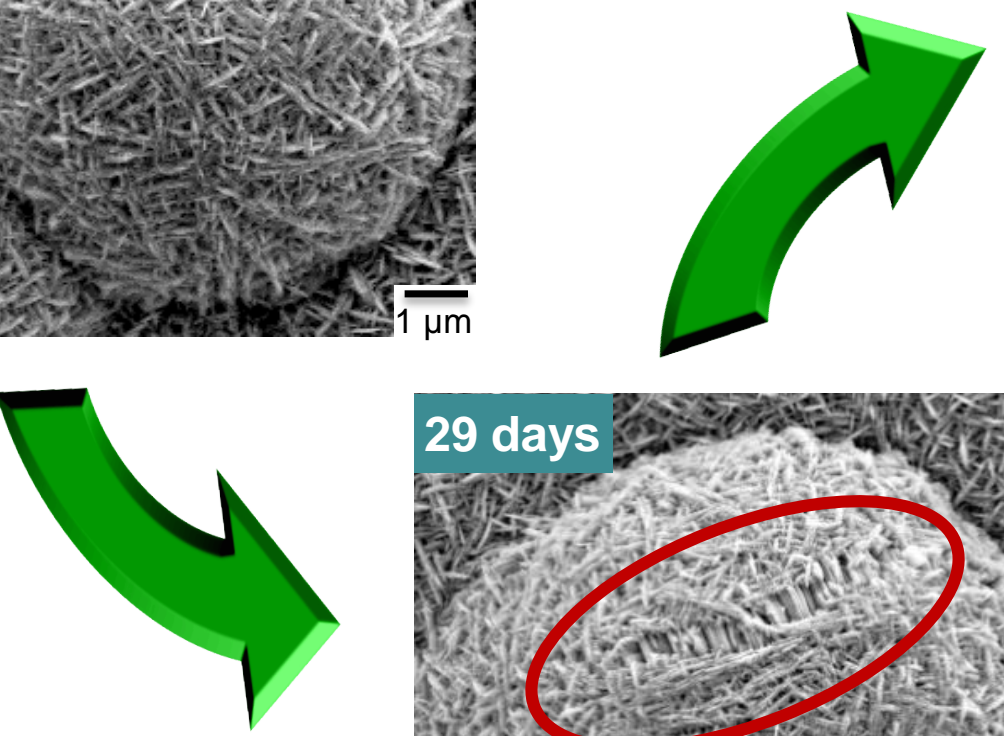

"Staircase structure" first appeared

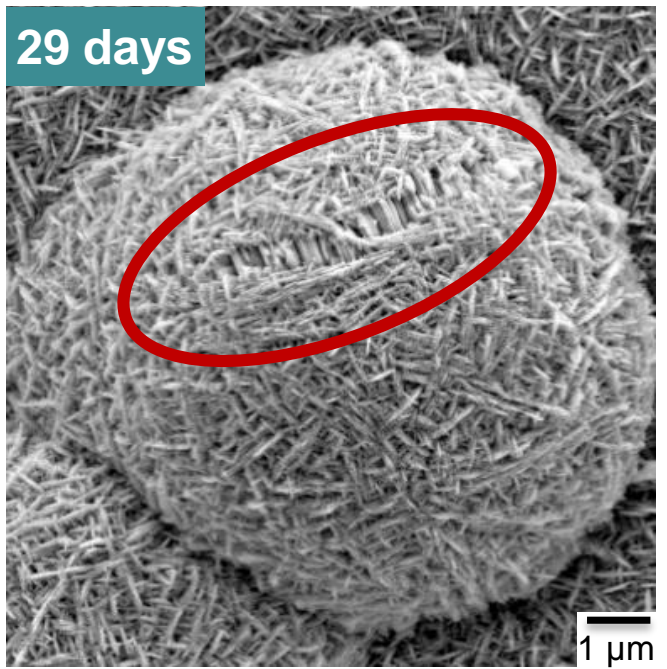

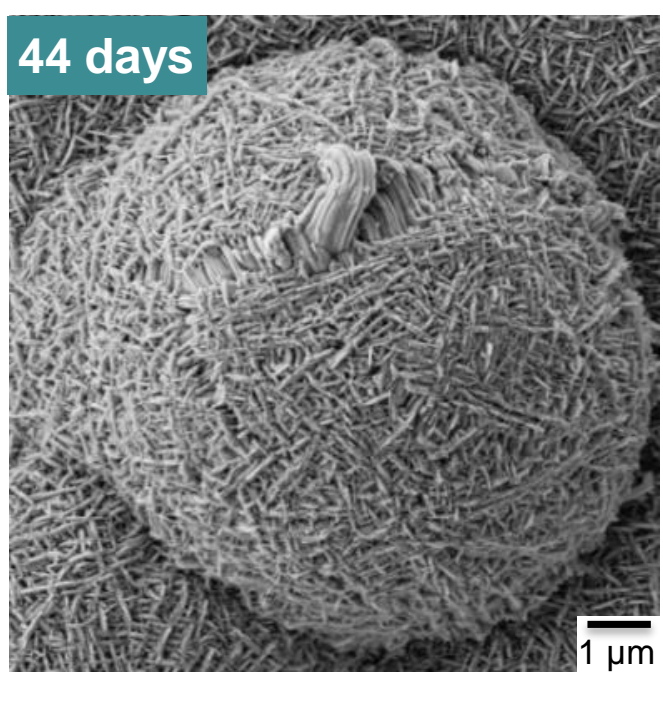

A whisker grew associated with the staircase structure
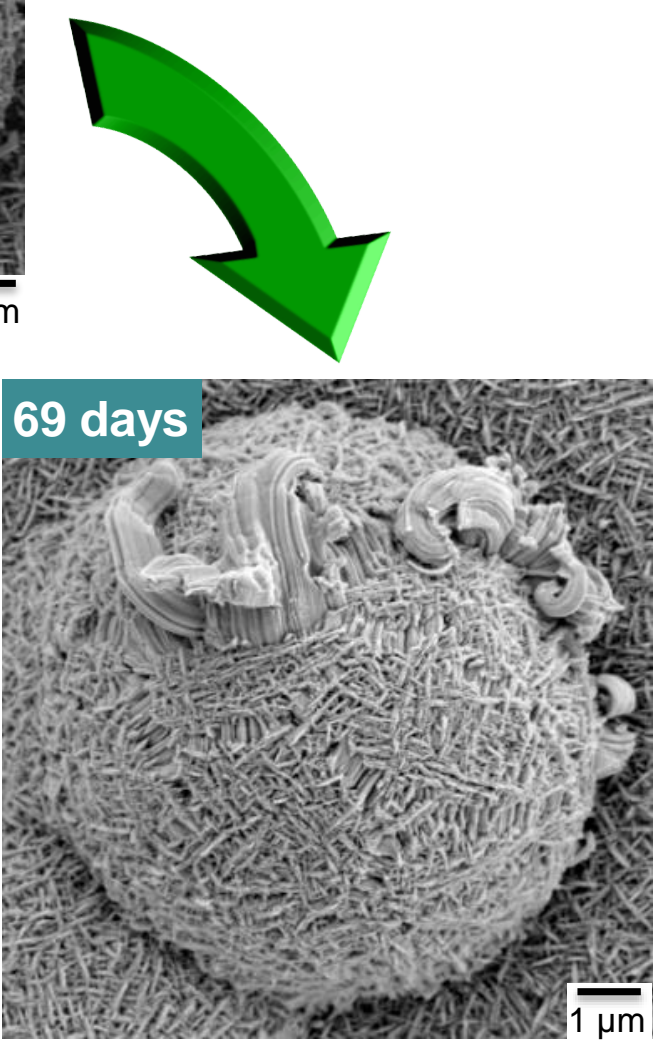

University

\section{Staircase Structures}

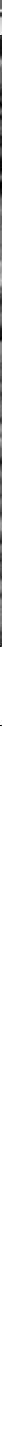




\section{Recrystallisation occurs Associated with Whisker Growth}

1. Whiskers growing associated with the nodules

Stored at RT for 6 months

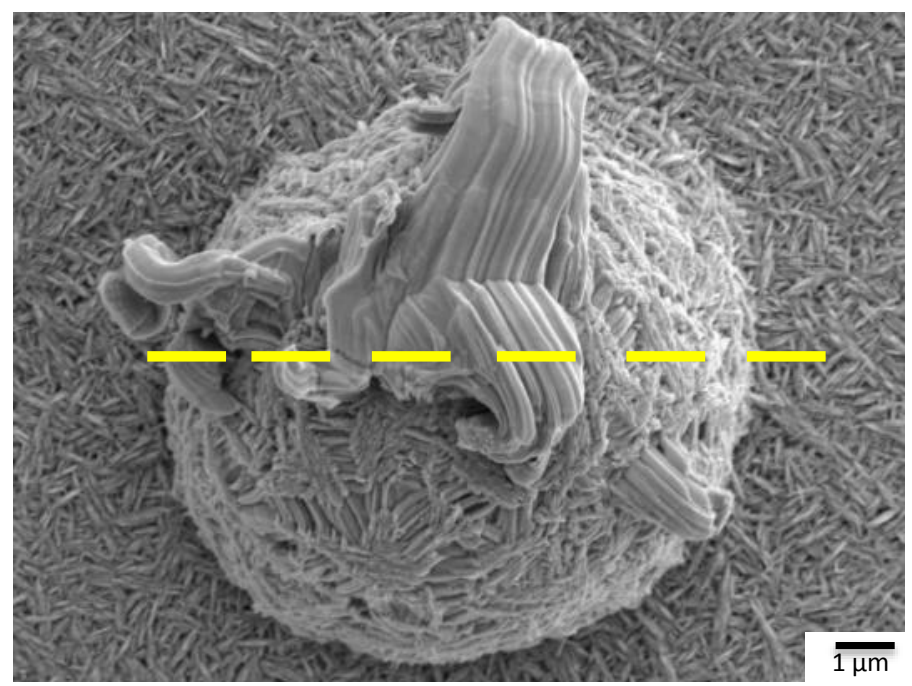

- A cavity was observed beneath the nodule

- Columnar grain structure in the flat deposit layer and also in the nodule

- Grains near whisker root were recrystallised
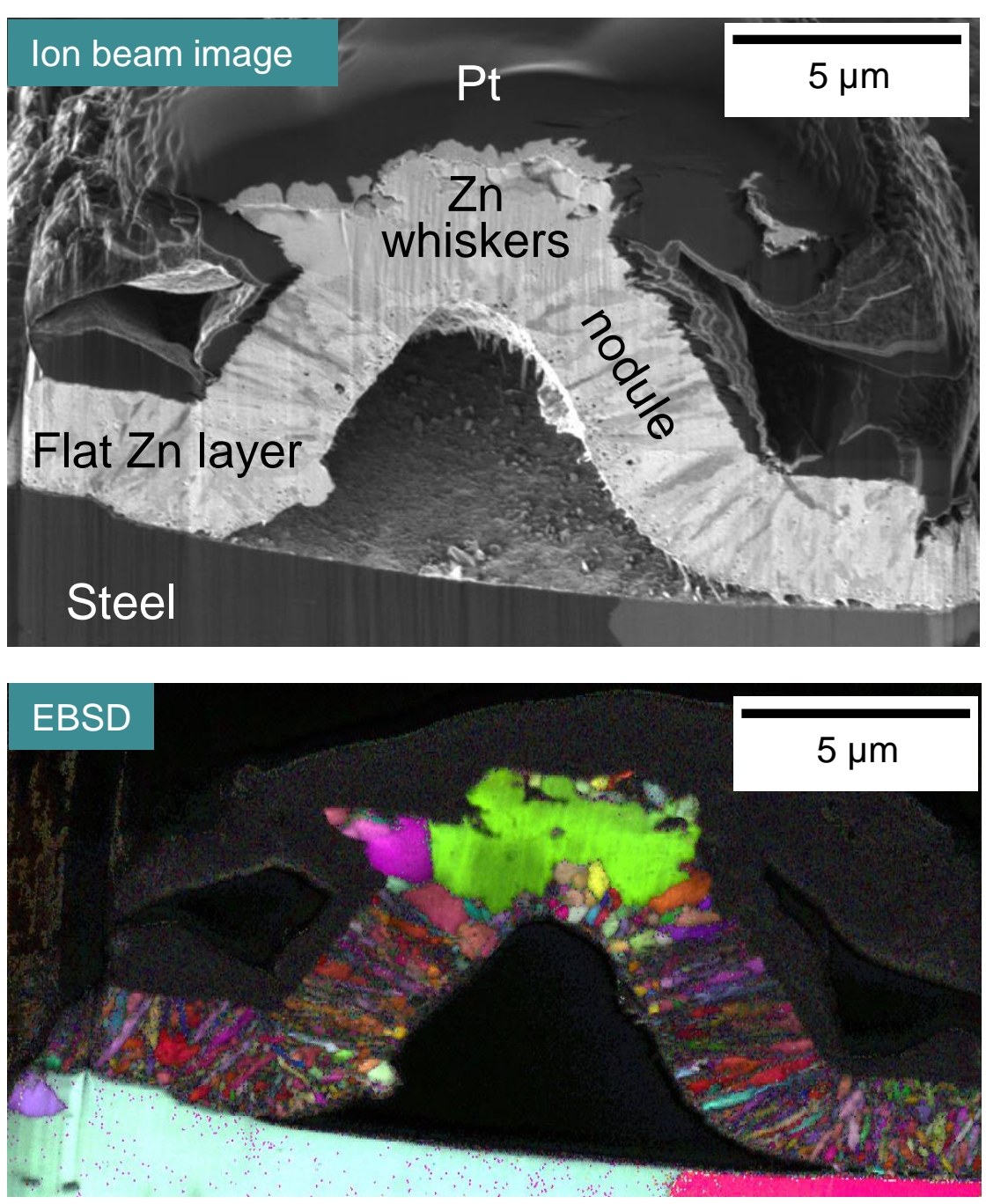


\section{Recrystallisation occurs Associated with Whisker Growth}

2. Whiskers growing from the flat deposit surface

Stored at RT for 6 months

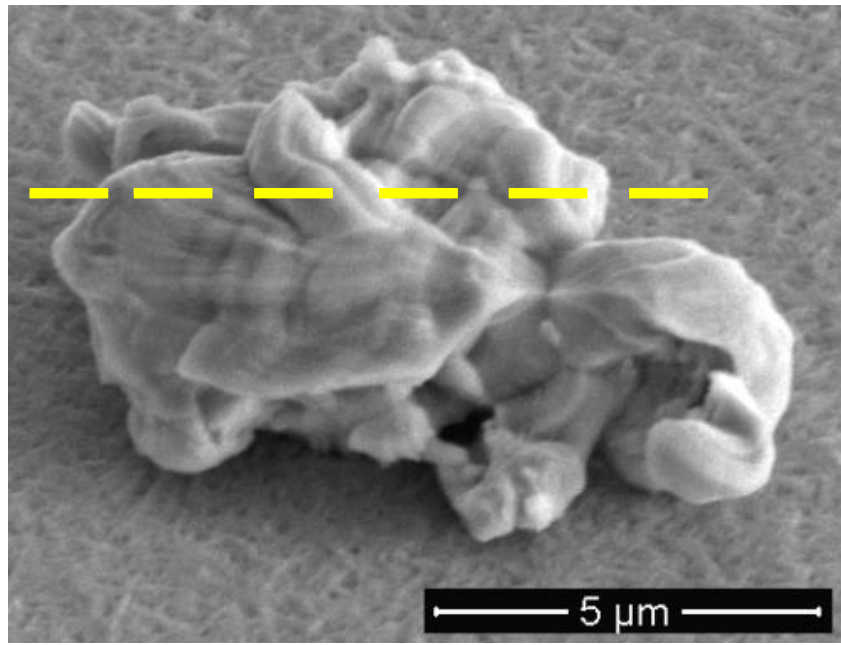

FIB crosssectioned

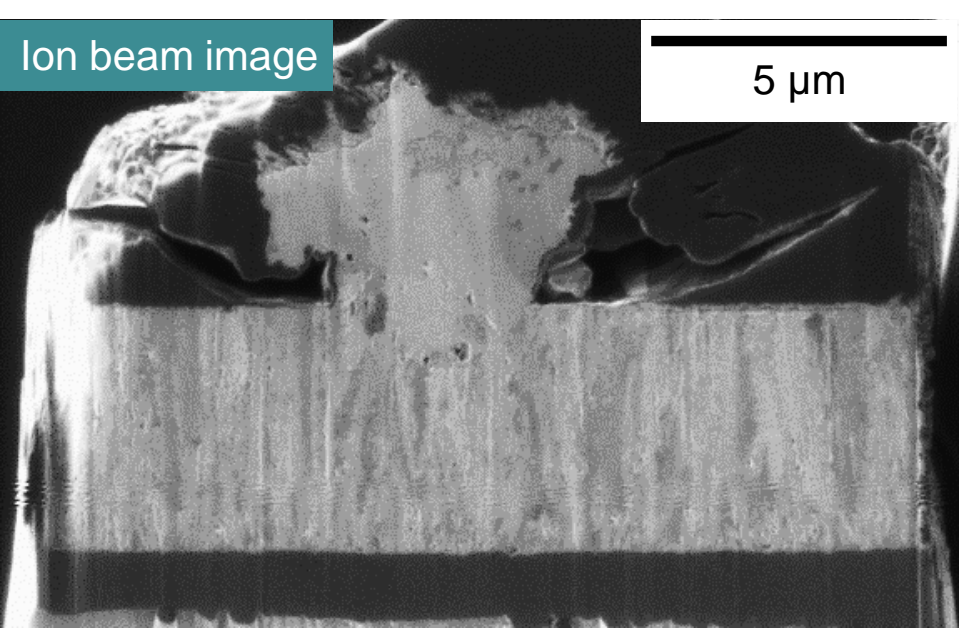

Recrystallisation occurs associated with whiskers growing from nodules and the flat deposit surface.

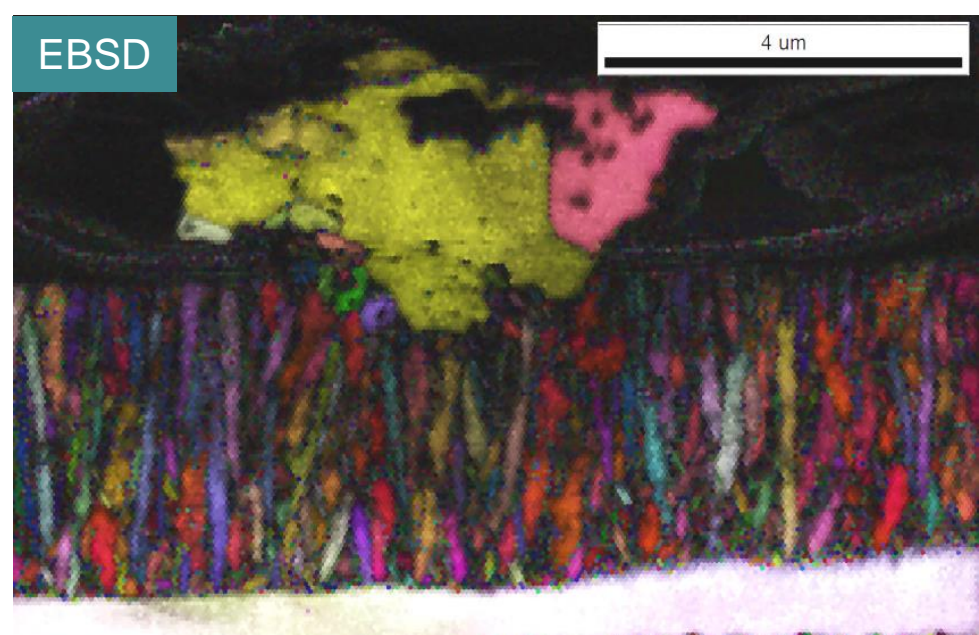




\section{Summary}

- Whisker growth from nodules was observed only 4 weeks after deposition; whilst whisker growth from the flat deposit surface was not observed until 5 months after deposition

- The presence of nodules and subsequent development of staircase structures markedly reduced the incubation time for whisker growth

- Lower deposition current density, thicker deposits \& heat treatment for $0.5 \mathrm{~h}$ at high temperatures resulted in fewer whiskers

- Recrystallisation is associated with whisker growth from both nodules and the flat deposit surface 


\section{Questions}

- Thank you for listening!

- Any questions or comments?

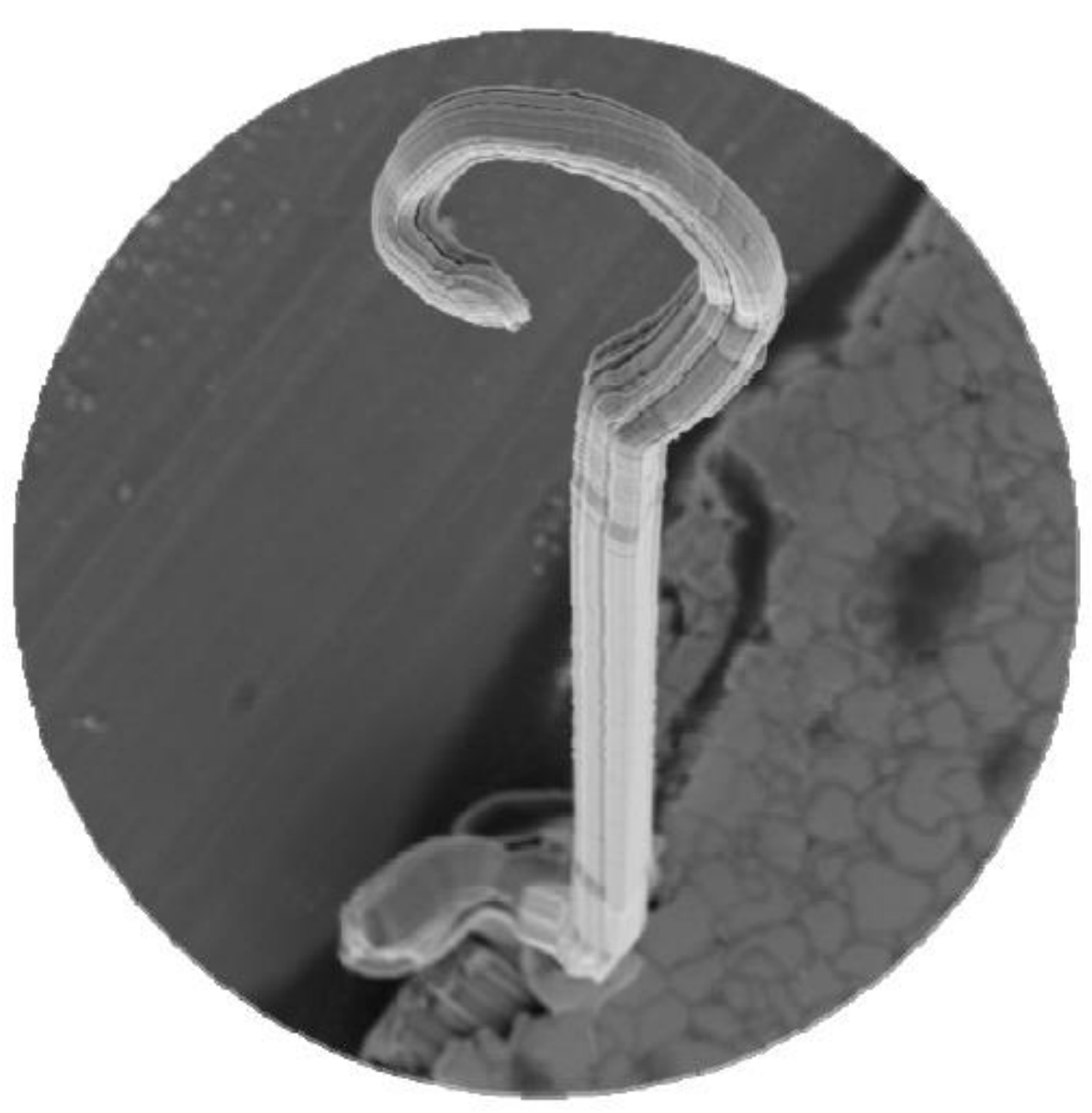

'Question mark' tin whisker from Dr Mark Ashworth 